\title{
INFLUENCE OF CUSTOMS PAYMENTS ON THE ECONOMIC SECURITY OF THE COUNTRY, PROBLEMS AND WAYS OF OVERCOMING
}

\author{
Inna KIYANCHUK' \\ Ternopil National Economic University, Ukraine
}

\begin{abstract}
The article considers the role of customs payments as one of the main revenue sources of the state budget of Ukraine. The volume of receipt of customs payments to the state budget is characterized. The structure of receipts from customs payments for 2016-2017 is considered. Problems that violate the stable level of economic security of the country are identified. The complex of measures proposed to resolve deficiencies in the system of collection of customs payments to the State Budget of Ukraine is considered. The purpose of this article is to reveal the content and role of revenues from customs payments to the state budget and their impact on the country's economic security. The subject of research: the impact of customs payments on the country's economic security. The methodological basis of the study is a set of general, scientific, specific scientific and special methods and approaches, which helped to realize the conceptual unity of the research. In particular: an integrated approach that is used to analyse the collection of customs payments methods of induction and deduction, formalization to study the mechanism of charging customs payments, the method of analysis - in the study of the main elements of the collection of customs payments in Ukraine. Positive and normative research methods are used to develop proposed budget revenues from receipt of customs payments and to ensure stable economic security. Results. Thus, according to the results of the analysis, in 2017, there is a clear tendency to increase revenues to the state budget, including from customs payments. Thus, in 2017, the total amount of customs payments amounted to 277.27 billion UAH, which is 57.24 billion UAH more than the previous year (220.03 billion UAH). That is, customs payments increased by $26 \%$. Economic implications. However, there are some problems in collecting customs payments to the state budget, which in turn violate a stable level of economic security of the state. To the problems that violate a stable level of economic security can be attributed: improper development of individual industries and industries that need to work efficiently and get further development in Ukraine, excessive customs duties can also lead to a shortage of goods in domestic markets and an increase in domestic prices. All this will negatively affect the economic security of the state. Therefore, when establishing customs duties, it is necessary to take into account their impact on the economic security, to predict the possible socio-economic consequences of the application of certain rates of customs duties. Conclusion. Taking into account the importance of customs payments in the formation of the State Budget and ensuring the economic security of Ukraine, we believe that the practice of charging customs payments in Ukraine requires the introduction of new ideas. In recent years, many interesting and effective methods of customs and tariff regulation have been applied in the world, which could be useful for Ukraine. At the present stage, the most appropriate is the use of the experience of the countries of Central and Eastern Europe, which recently joined the EU.
\end{abstract}

Key words: fiscal service of Ukraine, state budget of Ukraine, state economic security, customs payments, duties, value added tax, excise tax.

JEL Classification: H 200, H210, H220, H250

\section{1. Введение}

В статье рассмотрена роль таможенных платежей, как оАного из основных Аоходных источников госуАарственного бюджета Украины. Охарактеризованы объемы поступиения таможенных пиатежей в бюАжет государства. Проанализирована структура поступле- ний от таможенных платежей за 2016-2017 гг. ОпреАелены проблемы, которые нарушают стабильный уровень экономической безопасности страны. Рассмотрен комплекс мероприятий предложенных по решению неАостатков в системе взимания таможенных платежей в Государственный бюджет Украины.

Corresponding author:

${ }^{1}$ Department of Finance named after S.I. Yurii, Ternopil National Economic University.

E-mail: 09inna03@ukr.net 
Таможенная политика каждого государства играет важную роль в развитии финансово-экономических отношений. Четко и правильно построенная налоговая и таможенная системы в сфере внешнеэкономической деятельности делает существенное влияние на функционирование экономики в целом, и на все макроэкономические показатели развития государственного образования. Именно таможенные платежи выполняют одну из важнейших статей наполнения государственного бюАжета (Stal, 2015).

На сегоАняшний Аень процессы гмобализации и интернационализации влияют на экономику каждой страны, обуславливая ее зависимость от экзогенных факторов и вызывая рост экономических показателей или возникновения кризисных явлений в определенных секторах экономики. Не исключением является и Украина. Поэтому актуацьность приобретает обеспечение экономической безопасности государства от внутренних и внешних угроз, которые могут быть вызваны размичными явлениями. Это снижение доходов бюАжета, защите национального товаропроизводитемя, торговые войны и тому подобное.

Вопросы исследования таможенных пиатежей и их роль в развитии государства неоднократно становимись преАметом исследования таких ученых и практиков, как И. Бережнюк, И. Бураковский, А. Войцешук, $\Lambda$. Воронина, В. Геец, А. Гребельник, В. АуАчак, Ф. Жорин, А. Киреев, А. КреАисов, В. Мартынюк, К. Осадчая, П. Пашко, В. Покровская, В. Пятницкий, К. Санаровский, С. Терещенко, А. Тесленко и Ар.

ОтАельно стоит выделить работы А. В. Годованец, И. А. Гуцул, А. Ф. Запорожец, Т. Н. Стужук, в которых более подробно рассматриваются вопросы поступлений в государственный бюАжет от таможенных платежей.

Но, несмотря на Аостаточно большое количество научных наработок по этой теме, остаются открытыми многие вопросы о роли таможенных пиатежей в формировании государственного бюАжета, а также в обеспечении экономической безопасности страны. А именно вопросы, касающиеся решения проблем в системе взимания таможенных пиатежей в бюАжет, которые в свою очереАь нарушают стабильный уровень экономической безопасности государства.

Целью Аанной статьи является раскрытие содержания и роли поступлений от таможенных платежей в государственный бюАжет и их влияние на экономическую безопасность страны. Аостижение поставменной цели предполагает решение следующих задач: - охарактеризовать состав и Аинамику поступлений от таможенных платежей в Украине;

- определить роль таможенных платежей в формировании государственного бюджета и обеспечении экономической безопасности государства;
- выделить проблемы, которые нарушают стабильный уровень экономической безопасности госуАарства;

- преАложить направления повышения эффективности организации взимания таможенных платежей Аля обеспечения стабимьности экономической безопасности страны.

Методологической основой исследования явмяется совокупность общих, общенаучных, конкретно-научных и специальных методов и поАходов, что помогло в реализации концептуального единства исследования. В частности: комплексный подхоА, который используется Аля анализа взимания таможенных пиатежом, метоАЫ инАукции и АеАукции, формализации к изучению механизма взимания таможенных пиатежей, метод анализа - при исслеАовании основных элементов взимания таможенных платежей в Украине. Аля разработки преАложений по росту Аоходов бюАжета от поступления таможенных платежей и обеспечении стабильной экономической безопасности использован положительный и нормативный методы исследования.

\section{2. Экономическая суть таможенных пматежей}

Таможенный платеж - это разновидность обязательных пиатежей, взимаемых при перемещение или в связи с перемещением товаров через таможенную границу Украины (Voitschuk, 2007). Намоговый кодекс Украины определяет таможенные пиатежи как налоги, согласно Налоговому Кодексу Украины или таможенного законодательства взимаются при перемещении или в связи с перемещением товаров через таможенную границу Украины и контроль за взиманием которых положен на таможенные органы (The Tax Code of Ukraine, 2015).

Налоговым кодексом Украины установлено, что таможенные органы явмяются субъектами государственного контромя за пошиины, акцизного налога, налога на Аобавленную стоимость, согласно налоговым законодательством взимаются в случае ввоза товаров и преАметов на таможенную территорию Украины или территорию специальной таможенной зоны ими их вывоз из них (The Tax Code of Ukraine, 2015).

Из чего следует, что ввозная и вывозная пошлина, начисление которой предусмотрено на объекты экспортно-импортных операций, по действующему налоговому законодательству является оАним из винов налогов, то есть обязательным, безусловным платежом в бюАжет соответствующего уровня (The Tax Code of Ukraine, 2015). Вместе с НАС и акцизным налогом, пошиина относится к общегосударственным налогам (The Tax Code of Ukraine, 2015) следовательно, уплачивается в Государственный бюАжет Украины. 


\section{3. Анализ Аинамики поступиений от таможенных пиатежей}

Поэтому перейдем к анализу значения таможенных платежей в формировании государственного бюджета Украины за 2017 год и сравним эти Аанные с Аанными за 2016 год.

Таблица 1

Структура доходов государственного бюАжета Украины в 2016 и 2017 гг.

\begin{tabular}{|c|c|c|}
\hline Статья Аоходов & $\begin{array}{c}2017 \\
\text { (м^рА. грн.) }\end{array}$ & $\begin{array}{c}2016 \\
\text { (мирА. грн.) }\end{array}$ \\
\hline Налоговые поступцения & 606,02 & 502,56 \\
\hline $\begin{array}{l}\text { Налоги на Аоходы, налоги на } \\
\text { прибыль, налоги на увеличение } \\
\text { рыночной стоимости }\end{array}$ & 126,59 & 104,69 \\
\hline $\begin{array}{l}\text { Рента за использование } \\
\text { природных ресурсов }\end{array}$ & 48,09 & 62,50 \\
\hline $\begin{array}{l}\text { Внутренние налоги на товары и } \\
\text { ускуги }\end{array}$ & 406,44 & 314,55 \\
\hline $\begin{array}{l}\text { - в т. ч. акцииз с ввезенных в } \\
\text { Украину подакиизных товаров }\end{array}$ & 41,75 & 29,18 \\
\hline $\begin{array}{l}\text { - в т.ч. НАС с ввезенных в Украину } \\
\text { товаров }\end{array}$ & 212,76 & 171,20 \\
\hline $\begin{array}{l}\text { Налоги на межАународную } \\
\text { торговлю и внешние операции }\end{array}$ & 22,75 & 19,64 \\
\hline - в т. ч. ввозная почиина & 22,36 & 19,28 \\
\hline - в т. ч. вывозная почиина & 0,40 & 0,37 \\
\hline Местные налоги & 0,72 & 0 \\
\hline Экомогический налог & 1,42 & 1,17 \\
\hline Неналоговые поступления & 107,22 & 87,65 \\
\hline $\begin{array}{l}\text { ААминистративные сборы и } \\
\text { платежи }\end{array}$ & 7,02 & 5,48 \\
\hline Аругие ненамоговые поступления & 10,87 & 10,64 \\
\hline Официальные трансферты & 1,78 & 5,50 \\
\hline Цемевые фонды & 11,72 & 7,88 \\
\hline Всего Аоходов & 727,11 & 607,97 \\
\hline
\end{tabular}

Источник: построено по данным (Revenues of the State Budget of Ukraine, 2017)

Как видим из таблицы 1 , пошлина, акцизный налог с ввезенных на таможенную территорию Украины подакцизных товаров, налог на добавценную стоимость с ввезенных на таможенную территорию Украины товаров - оАин из главных Поставщиков Аенег Аһя госуАарственного бюАжета в 2017 году. ВеАь паАение курса гривны увеличивает цену импортного товара и, соответственно, и размер НАС и пошиины с него, кроме того, увеличены акцизы на импортируемый алкоголь и сигареты. Крупнейшими статьями доходов бюАжета в 2017 году, так же как и в преАыдущие годы, буАут: налог на Аобавленную стоимость (НАС) с импортных и украинских товаров, работ и услуг, налог на Аоходы физмиц (НАФ $\Lambda)$, налог на прибыль, рента за пользование неАрами и акцизы по нефтепродуктам, алкоголя и сигарет. Так, с ввезенных на территорию Украины товаров в 2017 году пианируется покучить 212,7 мирА. грн., что на 41,5 мирА. грн. больше, чем было заложено в бюАжете на 2016 гоА. НАС по импорту - самая большая статья доходов в бюджете. Аля сравнения, из произведенных товаров, работ и услуг в Украине планируется собрать 80,3 млрА. грн. НАС - на 19 ммрА. грн. больше по сравнению с бюАжетом 2016 года. Вырастут Аоходы от произведенных в Украине и импортированных подакцизных товаров. Как известно, в 2017 году значительно выросли акцизы на сигареты и алкоголь. От продажи подакцизных товаров, произведенных в Украине (алкоголь, сигареты, нефтепродукты) в 2017 году запланировано собрать 71,5 мирА. грн., что на 19 мирА. грн больше, чем в 2016 году. От импортируемых подакцизных товаров - 41,7 мирА. грн., что на 12,6 мирА. грн. больше, чем в 2016 году.

Налога на Аоходы физических миц планируется собрать 68,7 мирА. грн., Намога на прибыль преАприятий - 58 мирА. грн. Это соответственно на 2,5 мирА. грн. и 9,3 млрА. грн. больше запланированных поступлений в 2016 году. ГАавным наполнителем бюджета в разделе неналоговых поступлений в 2017 году будет Национахьный банк, который обязали перечислить не менее 45 млрА. грн. Это на 7 мирА. грн. больше, чем НБУ перечислил в 2016 году. В целом доходы государственного бюАжета 2017 вырастут на 119 мира. грн. - Ао 727 мирА. грн. (см. таблицу 1).

Таким образом, по результатам проведенного анамиза, в 2017 году прослеживается четкая тенденция увеличения поступлений в госуАарственный бюАжет, в том числе и от таможенных платежей.

Наибольший удельный вес в составе таможенных платежей в 2017 году занимает налог на Аобавленную стоимость с ввезенных на территорию Украины товаров - 212,76 мира. грн., или около 76,7\% (рис. 1). В 2016 году поступмения от этого намога в структуре таможенных пиатежей составцяли 171,20 мирА. грн., или около 77,8\% (рис. 2).

Вторым по значению явмяется акциз с ввезенных в Украину подакцизных товаров. Ввозная пошиина находится на третьей позиции, и замыкает список вывозная пошиина, поступления от которой находятся в пределах 0,1-0,2\% от всех таможенных платежей. Таким образом, по результатам проведенного анализа, в 2017 году прослеживается четкая тенденция увекичения поступлений в госуАарственный бюАжет, в том числе и от таможенных платежей. Так, в 2017 году общая сумма таможенных платежей составила 277,27 мирА. грн., что на 57,24 млрА. грн. больше преАылущего гоАа (220,03 мира. грн.). То есть таможенные платежи выросли на $26 \%$. 


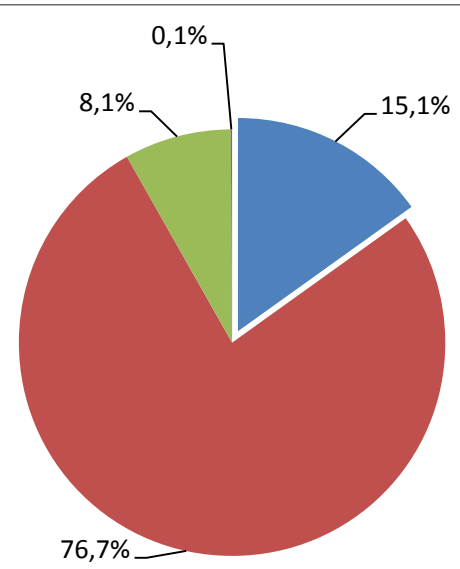

- Акциз с ввезенных в Украину подакцизных товаров - НДС с ввезенных в Украину товаров

—возная пошлина

- Вывозная пошлина

Рис. 1. Структура поступмений

от таможенных пматежей в 2017 г.

Источник: построено автором по данным таблицы 1

\section{4. Определение проблем экономической безопасности госуАарства}

ОАнако существуют некоторые проблемы во взимании таможенных пиатежей в государственный бюАжет, которые в свою очередь нарушают стабильный уровень экономической безопасности государства. В общем, стабильный уровень экономической безопасности - это показатемь успешного развития государства, его экономики. Эффективная система обеспечения экономической безопасности - вопрос жизни мюбого государства, стремящегося занять Аостойное место в мировом геополитическом и экономическом пространстве.

К проблемам, которые нарушают стабильный уровень экономической безопасности можно отнести:

1. Несовершенное развитие отдельных производств и отраслей, которые Аолжны эффективно работать и получать Аальнейшее развитие в Украине. В условиях, когАа отечественная промышленность, которая производит товар, аналогичный импортному товару, недостаточно конкурентоспособна, возникает необходимость в ее защите на то время, когАа она сможет Аостичь уровня конкурентоспособности. Важно правильно обосновать и рассчитать уровень таможенной защиты. Недостаточный уровень защиты приведет к постепенной нерентабельности и миквиАации собственного производства товара, увольнения работников, рост безработицы, а вПослеАствии - и снижение поступлений в бюАжет. А чрезмерный - будет созАавать препятствия конкуренции на рынке, что впослеАствии также отрицательно повлияет на отечественного производителя,

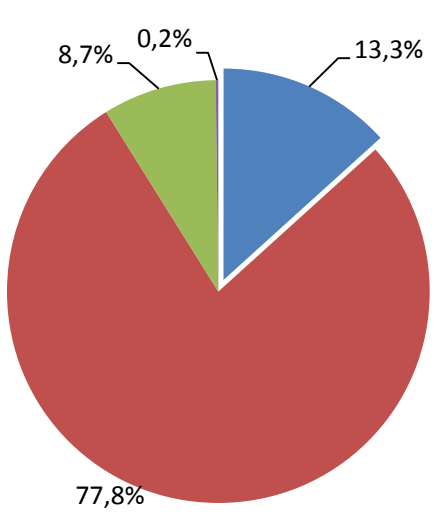

- Акциз с ввезенных в Украину подакцизных товаров

- НДС с ввезенных в Украину товаров

- Ввозная пошлина

в Вывозная пошлина

Рис. 2. Структура поступмений

от таможенных пматежей в 2016 г.

Источник: построено автором по данным таблицы 1

который начнет производить продукцию неАостаточного качества по завышенной стоимости.

2. Чрезмерные таможенные ставки также могут приводить к созданию дефицита товаров на внутренних рынках и рост внутренних цен. Все это отрицательным образом отразится на экономической безопасности государства. Поэтому при установлении таможенных пиатежей, необходимо учитывать их вмияние на экономическую безопасность, прогнозировать возможные социально-экономические послеАствия применения тех или иных ставок пошиин.

Значение таможенных платежей Амя обеспечения экономической безопасности в рассматриваемом аспекте явмяется следующим:

- таможенные платежи создают стоимостный барьер, что повышает цену импортного товара при его Авижении на внутренний рынок страны или при вывозе сырья на мировой рынок;

- выборочно повышая или понижая ставки таможенных платежей, государство может стимулировать развитие определенных отраслей экономики;

- таможенные пиатежи (в разрезе ввозных пошиин) защищают опреАеленные отрасли экономики от конкуренции иностранных товаров и создают национальным производителям условия, позволяющие им конкурировать с иностранными товаропроизводителями;

- таможенные платежи могут широко использоваться в качестве рычага давления на стран-экспортеров с целью заставить их пойти на определенные уступки; 
- таможенные платежи явмяются эффективным инструментом интеграции страны в мировую экономику, обеспечение ее конкурентоспособности на межаународных рынках.

Совершенствование системы взимания таможенных платежей является важным фактором влияния на положительную Аинамику относительно полноты поступлений таможенных налогов и сборов в госуАарственный бюАжет, что в свою очередь обеспечат стабильность экономической безопасности государства. Наиболее эффективным способом увеличения АохоАов бюАжета от взимания таможенных пиатежей явцяется правильное определение величины базы налогообложения - таможенной стоимости товаров. Именно таможенная стоимость влияет на объемы таможенных пиатежей, а также на уровень импортных цен на внутреннем рынке. Стоит также отметить о нарушении субъектами внешнеэкономической Аеятельности налогового и таможенного законодательства, несовершенной структуре внешнеторговых потоков, отрицательном сальдо торгового баланса, отдельных недостатках нормативно-правового обеспечения налогового регумирования ВЭА, несовершенства системы предоставления мьгот. Также существуют проблемы в организации контромя за соблюдение таможенного законодательства субъектами ВЭА и гражАанами (Pashko \& Berezhnyuk, 2013).

Существует ряА проблем во взимании акцизного налога, что обусловлено неструктурированными ставками на подакцизные товары. С целью усовершенствования акцизного налогообложения внешнеторговых потоков считаем необходимым ввести научно обоснованный уровень и структуру ставок акцизного налога, что усилит выполнения им регулирующей функции путем постепенного увеличения доли акциза в цене импортной подакцизной продукции. Требует совершенствования механизм автоматического возмещения НАС экспортерам, поскольку невозмещение ими несвоевременное возмещение сумм такого налога приводит к росту цены экспортируемой продукции и снижение ее конкурентоспособности на мировом рынке (Pashko \& Berezhnyuk, 2013).

\section{5. ВЫводЫ из Аанного иссиеАования и перспективы}

Итак, из провеАенного исследования можно сАемать вывоА, что таможенные платежи явмяются весомым наполнителем государственного бюАжета Украины, и имеют один из решающих факторов в формировании стабильной экономической безопасности государства. Хотя в системе взимания таможенных пиатежей существует ряА неАостатков и проблем, требующих неотможного решения.

В последние годы в мире применено много интересных и эффективных приемов таможенно-тарифного регумирование, которые могли бы бить полез- ными Аля использование в Украине. На современном этапе наиболее поАхоАящим является использование опыта стран Центрацьной и Восточной Европы, которые недавно присоединились к ЕС. Он заключается в соблюдение низких тарифных ставок на большинство товарных позиций, особенно с низкой степенью пропитки и особую защиту некоторых отраслей сельского хозяйства и машиностроения. Как показывает опыт стран-чменов Европейского Союза, с помощью только таможенных платежей нельзя обеспечить защиту национального товаропроизводитеця, эффективно явцяется его сочетание с антидемпинговыми расследованиями, нетарифными методами регулирования и субсидиями национальным товаропроизводитемям.

Учитывая большое значение таможенных платежей в формировании государственного бюджета и обеспечении экономической безопасности Украины, считаем, что механизм взимания таможенных пиатежей в Украине требует внеАрения новых приемов и идей.

Повышение эффективности организации взимания таможенных платежей и обеспечить стабильность экономической безопасности можно Аостичь за счет:

- активизации сотрудничества с производителями и импортерами товаров в части получения справочной информации о ценах и факторах, влияющих на их уровень;

- проведения анализа классификационных решений традиционного импорта;

- сохранение необходимого уровня тарифной защиты отАельных отраслей, имеющих низкую конкурентоспособность;

улучшение организационно-правового обеспечения Аеятельности контролирующих органов;

- разработка и установление оптимального уровня таможенных пиатежей с цемью повышения инвестиционной привлекательности отАельных отраслей украинской промышиенности и сельского хозяйства; - усиление контроля таможенных органов за правильностью классификации и определения страны происхожАения товаров, в отношении которых установлены Аифференцированные ставки ввозной пошиины и специальные и антидемпинговые меры.

Решением этих вопросов позволит повысить качество таможенного регулирования и усовершенствовать процесс взимания таможенных пиатежей в Украине, что в свою очередь будет способствовать увеличению поступиений в госуАарственный бюАжет страны, и подАерживать стабильный уровень экономической безопасности, а как мы отметили выше - эффективная и качественная система обеспечения экономической безопасности - вопрос жизни

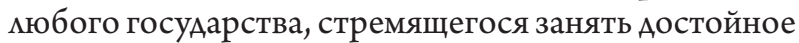
место в мировом геополитическом и экономическом пространстве. 


\section{References:}

Stal T. (2015). Customs payments of Ukraine and influence on their membership in the world trade organization. Theoretical and practical aspects of economy and intellectual property,1(2):192-196.

Voitschuk A. (2007). Regulation of customs: Textbook for stud. Higher Teach Shut off. - Khmelnitsky, Intrada, p. 312 .

The Tax Code of Ukraine: As of October 1, (2015) - K.: My Book, p. 592.

Pashko P., \& Berezhnyuk I. (2013). Customs policy and customs security of Ukraine: monograph - Khmelnitsky, $338 \mathrm{p}$.

Revenues of the State Budget of Ukraine for (2017). Electronic resource, Liga Law: Legal portal. - Access mode: http://search.ligazakon.ua/1_doc2.nsf/link1/T161801.html

\section{Инна КИЯНЧуК \\ ВЛИЯНИЕ ТАМОЖЕННЫХ ПЛАТЕЖЕЙ НА ЭКОНОМИЧЕСКУЮ БЕЗОПАСНОСТЬ СТРАНЫ, ПРОБЛЕМЫ И ПУТИ ПРЕОДОЛЕНИЯ}

Аннотация. В статье рассмотрена роль таможенных платежей, как одного из основных доходных источников государственного бюджета Украины. Охарактеризованы объемы поступления таможенныхплатежей в бюджет государства. Проанализирована структура поступлений от таможенныхплатежей за 2016-2017 гг. Определены проблемы, которые нарушают стабильный уровень экономической безопасности страны. Рассмотрен комплекс мероприятий предложенных по решению недостатков в системе взимания таможенных платежей в Государственный бюджет Украины. Цель этой статьи - выявить содержание и роль доходов от таможенных платежей в государственный бюджет и их влияние на экономическую безопасность страны. Предмет исследования: влияние таможенных платежей на экономическую безопасность страны. Методологической основой исследования является совокупность общих, общенаучных, конкретно-научных и специальных методов и подходов, что помогло в реализации концептуального единства исследования. В частности: комплексный подход, который используется для анализа взимания таможенных платежей, методы индукции и дедукции, формализации к изучению механизма взимания таможенных платежей, метод анализа - при исследовании основных элементов взимания таможенных платежей в Украине. Для разработки предложений по росту доходов бюджета от поступления таможенных платежей и обеспечении стабильной экономической безопасности использован положительный и нормативный методы исследования. Результаты. Таким образом, согласно результатам анализа, в 2017 году наблюдается явная тенденция увеличения поступлений в государственный бюджет, в том числе от таможенных платежей. Так, в 2017 году общий объем таможенных платежей составил 277,27 млрд. грн., Что составляет 57,24 млрд. грн. больше, чем в предыдущем году (220,03 млрд. грн.). То есть таможенные платежи увеличились на 26\%. Экономические последствия. Однако есть некоторые проблемы в сборе таможенных платежей в государственный бюджет, что, в свою очередь, нарушает стабильный уровень экономической безопасности государства. К проблемам, которые нарушают стабильный уровень экономической безопасности, можно отнести: ненадлежащее развитие отдельных отраслей и отраслей, которые должны эффективно работать и получать дальнейшее развитие в Украине, чрезмерные таможенные пошлины также могут привести к нехватке товаров на внутренних рынках и увеличение внутренних цен. Все это отрицательно скажется на экономической безопасности государства. Поэтому при установлении таможенных пошлин необходимо учитывать их влияние на экономическую безопасность, прогнозировать возможные социально-экономические последствия применения определенных ставок таможенных пошлин. Вывод. Принимая во внимание важность таможенных платежей при формировании государственного бюджета и обеспечении экономической безопасности Украины, мы считаем, что практика взимания таможенных платежей в Украине требует введения новых приемов и идей. В последние годы в мире применено много интересных и эффективных приемов таможенно-тарифного регулирование, которые могли бы быть полезными для использования в Украине. На современном этапе наиболее подходящим является использование опыта стран Центральной и Восточной Европы, которые недавно присоединились к ЕС. 